Article

\title{
Profiling Anticancer and Antioxidant Activities of Phenolic Compounds Present in Black Walnuts (Juglans nigra) Using a High-Throughput Screening Approach
}

\author{
Khanh-Van Ho ${ }^{1,2}{ }^{\oplus}$, Anuradha Roy ${ }^{3}$, Sarah Foote ${ }^{4}$, Phuc H. Vo ${ }^{1}$, Namrita Lall ${ }^{1,5}$ \\ and Chung-Ho Lin ${ }^{1, *}$ \\ 1 Center for Agroforestry, School of Natural Resources, University of Missouri, Columbia, MO 65211, USA; \\ vkh6c6@mail.missouri.edu (K.-V.H.); phucvh2410@gmail.com (P.H.V.); namrita.lall@up.ac.za (N.L.) \\ 2 Department of Food Technology, Can Tho University, Can Tho 90000, Vietnam \\ 3 High Throughput Screening Laboratory, University of Kansas, Lawrence, KS 66047, USA; anuroy@ku.edu \\ 4 CEVA Biomune, Lenexa, KS 66215, USA; sarah.foote@ceva.com \\ 5 Department of Plants and Soil Sciences, Plant Science Complex, University of Pretoria, \\ Pretoria 0002, South Africa \\ * Correspondence: LinChu@missouri.edu; Tel.: + 573-884-6302
}

Academic Editor: Francesco Cacciola

Received: 7 September 2020; Accepted: 30 September 2020; Published: 2 October 2020

check for updates

\begin{abstract}
Our recent studies have demonstrated multiple health-promoting benefits from black walnut kernels. These biological functions of black walnuts are likely associated with their bioactive constituents. Characterization of phenolic compounds found in black walnut could point out underexplored bioactive activities of black walnut extracts and promote the development of novel applications of black walnut and its by-products. In the present study, we assessed bioactivity profiles of phenolic compounds identified in the kernels of black walnuts using a high-throughput screening (HTS) approach. Black walnut phenolic compounds were evaluated in terms of their total antioxidant capacity, antioxidant response element (ARE) induction, and anticancer activities. The anticancer activities were identified by evaluating the effects of the phenolic compounds on the growth of the tumorigenic alveolar epithelial cells (A549) and non-tumorigenic lung fibroblast cells (MRC-5). Out of 16 phenolic compounds tested, several compounds (penta- $O$-galloyl- $\beta$-D-glucose, epicatechin gallate, quercetin, (-)-epicatechin, rutin, quercetin 3- $\beta$-D-glucoside, gallic acid, (+)-catechin, ferulic acid, syringic acid) exerted antioxidant activities that were significantly higher compared to Trolox, which was used as a control. Two phenolic compounds, penta-O-galloyl- $\beta$-D-glucose and quercetin 3- $\beta$-D-glucoside, exhibited antiproliferative activities against both the tumorigenic alveolar epithelial cells (A549) and non-tumorigenic lung fibroblast cells (MRC-5). The antioxidant activity of black walnut is likely driven not only by penta- $O$-galloyl- $\beta$-D-glucose but also by a combination of multiple phenolic compounds. Our findings suggested that black walnut extracts possibly possess anticancer activities and supported that penta- $O$-galloyl- $\beta$-D-glucose could be a potential bioactive agent for the cosmetic and pharmaceutical industries.
\end{abstract}

Keywords: penta-O-galloyl- $\beta$-D-glucose; polyphenol; antioxidant response element

\section{Introduction}

Black walnut (Juglans nigra L.) is an economically valuable tree for edible nut production in the United States [1]. This native tree nut constitutes a major part of the nut production industry in the U.S. Midwest, with over 15 million pounds processed annually in Missouri [2]. People traditionally 
valued black walnut kernels as a health-promoting food source based on its compositional profile and utilized other parts of the trees (e.g., leaves, barks) for multiple medical purposes to treat diarrhea and bilious and cramp colic [3]. Consumption of black walnut kernels has been linked to potential health-promoting activities, such as lowering cholesterol absorption, anti-inflammatory effects, and prevention of certain cancers [4].

Our recent studies have demonstrated a wide range of biological functions of kernel extracts derived from black walnuts including antibacterial, antioxidant, and anti-inflammatory potential [5-7]. Ho et al. [6] reported antibacterial capacities of 22 black walnut cultivars selected for nut production by the University of Missouri Center for Agroforestry (Columbia, Missouri, USA) [8]. Several black walnut cultivars (e.g., Mystry, Surprise) exhibited antibacterial activity against a Gram-positive bacterium (Staphylococcus aureus) and the antibacterial activities were variable among the tested cultivars. Glansreginin A, azelaic acid, and quercetin were predominant phenolic compounds responsible for the antibacterial activities. These compounds were successfully identified in the bioactive fraction of kernel extracts from Mystry via a bioassay guided purification strategy combined with a metabolomics approach [6].

Black walnut kernels have also been reported to possess anti-inflammatory potential. The kernel extracts of black walnuts exhibited inhibitory effects on the production of several anti-inflammatory mediators (e.g., interleukin (IL)-1 $\beta$, tumor necrosis factor alpha (TNF- $\alpha$ ), monocyte chemoattractant protein (MCP)-1, IL-6, IL-8) in human promonocytic cell line U-937 model system [5]. The cytokine suppressive activities were variable among the black walnut cultivars examined. Two cultivars, Surprise and Sparrow, significantly inhibited the cytokine production of all examined cytokines in the U-937 cells. Additionally, our recent findings revealed antioxidant activities of the kernel extracts derived from six black walnut cultivars. Mystry showed the strongest antioxidant capacities compared with other tested cultivars [7].

Health-promoting properties of black walnuts are likely associated with a wealth of phytochemicals presented in black walnut kernels. Several polyphenols detected in the kernel extracts of black walnut are known to possess a variety of bioactive functions such as anti-inflammatory, antioxidant, antibacterial, and anticancer activities. Our previous studies have identified 17 phenolic compounds in the kernels of 11 black walnut cultivars [6,9] and many of these compounds (e.g., ellagic acid, epicatechin gallate, naringin, penta-O-galloyl- $\beta$-D-glucose, quercetin-3- $\beta$-D-glucoside) are known to possess antioxidant and anticancer activity [10-12].

High-throughput screening (HTS) is a critical tool to expand biomedical knowledge of small molecules that can be used for the drug discovery industry [13]. The high-throughput analytical technologies enable us to evaluate the biological functions of large amounts of chemicals or natural materials in the shortest amount of time by integrating chemical analyses, modeling, and machine learning that can result in marketed pharmaceutical products in the lowest cost production [14]. In this study, we utilized high-throughput screening assays to identify antioxidant and anticancer potentials of phenolic compounds found in black walnuts. The exploration of biological functions of bioactive compounds in black walnuts could reveal underexplored bioactive activities of black walnut extracts and promote the development of novel applications of black walnut and its by-products.

\section{Results}

\subsection{Total Antioxidant Capacity}

Our previous studies have documented the presence of 17 phenolic compounds in black walnuts [6,9]. Out of 17 phenolic compounds identified, 16 compounds were evaluated for their antioxidant and anticancer activities, whereas the bioactive activities of glansreginin A were not examined since this compound was not commercially available. Out of 16 phenolic compounds tested, 10 compounds (penta-O-galloyl- $\beta$-D-glucose, epicatechin gallate, quercetin, (-)-epicatechin, rutin, quercetin 3- $\beta$-D-glucoside, gallic acid, (+)-catechin, ferulic acid, syringic acid) exhibited higher total 
antioxidant capacity compared with the control (Trolox). Six phenolic compounds including vanillic acid, ellagic acid, naringin, $p$-coumaric acid, $p$-hydroxybenzoic acid, and quinic acid had lower total antioxidant capacity than Trolox (Figure 1). The fold-increase over Trolox of these phenolic compounds ranged from 1.1 to 11.5 . Penta-O-galloyl- $\beta$-D-glucose exhibited the highest total antioxidant capacity, followed by epicatechin gallate, quercetin, (-)-epicatechin, rutin, quercetin 3- $\beta$-D-glucoside, gallic acid, (+)-catechin, ferulic acid, and syringic acid, respectively (Table 1).

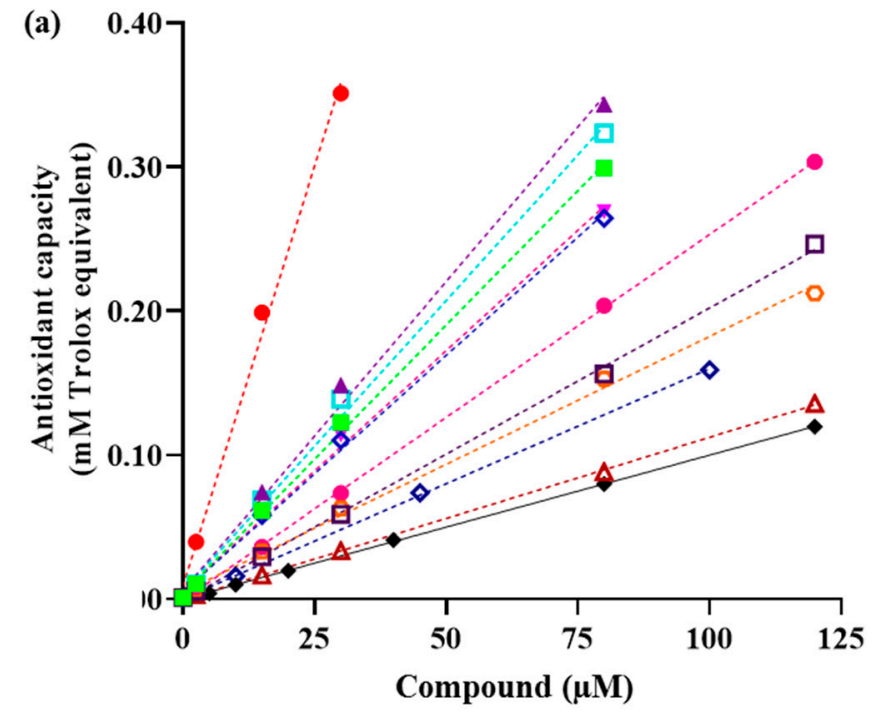

- Penta- $O$-galloyl- $\beta$-D-glucose

- ․ㅡㄹ- (-)-Epicatechin

^- Epicatechin gallate

ㅁ. (+)-Catechin

๑. Ferulic acid

-. Gallic acid

ㅁ. Quercetin

๑. Quercetin 3- $\beta$-D-glucoside

$\triangle$ - Syringic acid

$-\nabla$ Rutin

$\diamond$ DL-Sulforaphane

^ Trolox

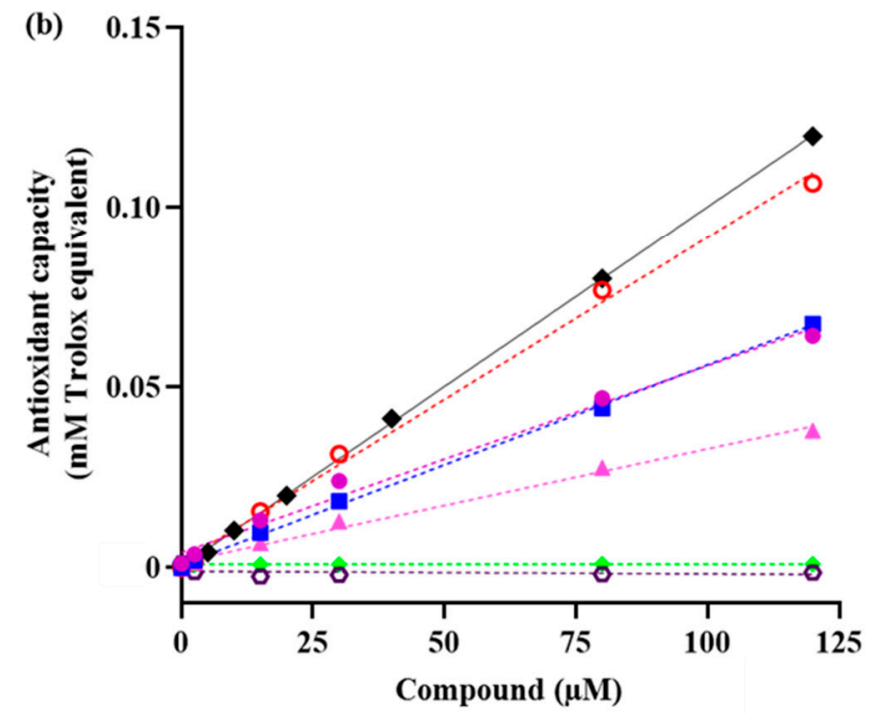

- Ellagic acid

- Naringin

- p-Coumaric acid

o. $p$-Hydroxybenzoic acid

-. Quinic acid

๑. Vanillic acid

- Trolox

Figure 1. Total antioxidant activity of phenolic compounds in black walnut. (a) Compounds with higher antioxidant capacity than Trolox, (b) compounds with lower antioxidant capacity than Trolox.

Linear regression models of the majority of tested compounds had high $R^{2}$ values $(>0.98)$, indicating that these models were reliable (Table 1). Models of two compounds ( $p$-hydroxybenzoic acid and quinic acid) had low values of $\mathrm{R}^{2}$ since these compounds had minor or no antioxidant capacity under the experimental conditions. Violin plots representing the data distribution of controls (Trolox and tert-butylhydroquinone) showed a relatively small variation of data, indicating that the HTS assay system was reliable (Supplementary Figures S1 and S2). 
Table 1. Antioxidant activities of phenolic compounds in black walnut.

\begin{tabular}{|c|c|c|c|c|}
\hline No. & Compound & $\begin{array}{c}\text { Slope } \\
\text { (in Trolox Equivalents) }\end{array}$ & R Square & $\begin{array}{c}\text { Fold-Increase } \\
\text { Over Trolox }\end{array}$ \\
\hline \multicolumn{5}{|c|}{ Control } \\
\hline 1 & Trolox & $0.001014 \pm 1.125 \times 10^{-5}$ & 0.999 & 1.0 \\
\hline \multicolumn{5}{|c|}{ Antioxidant Capacity Higher than Trolox } \\
\hline 2 & Penta-O-galloyl- $\beta$-D-glucose & $0.01167 \pm 5.756 \times 10^{-4}$ & 0.995 & 11.5 \\
\hline 3 & Epicatechin gallate & $0.004294 \pm 1.570 \times 10^{-4}$ & 0.996 & 4.2 \\
\hline 4 & Quercetin & $0.004045 \pm 1.392 \times 10^{-4}$ & 0.997 & 4.0 \\
\hline 5 & (-)-Epicatechin & $0.003729 \pm 7.546 \times 10^{-5}$ & 0.999 & 3.7 \\
\hline 6 & Rutin & $0.002962 \pm 1.551 \times 10^{-4}$ & 0.989 & 2.9 \\
\hline 7 & Quercetin 3- $\beta$-D-glucoside & $0.002908 \pm 1.522 \times 10^{-4}$ & 0.989 & 2.9 \\
\hline 8 & Gallic acid & $0.002541 \pm 1.392 \times 10^{-5}$ & 0.999 & 2.5 \\
\hline 9 & $(+)$-Catechin & $0.002029 \pm 3.184 \times 10^{-5}$ & 0.999 & 2.0 \\
\hline 10 & Ferulic acid & $0.001775 \pm 5.026 \times 10^{-5}$ & 0.997 & 1.8 \\
\hline 11 & Syringic acid & $0.001088 \pm 1.057 \times 10^{-5}$ & 0.999 & 1.1 \\
\hline \multicolumn{5}{|c|}{ Antioxidant capacity lower than Trolox } \\
\hline 12 & Vanillic acid & $0.0007396 \pm 4.245 \times 10^{-5}$ & 0.984 & 0.7 \\
\hline 13 & Ellagic acid & $0.0005183 \pm 2.860 \times 10^{-5}$ & 0.988 & 0.5 \\
\hline 14 & Naringin & $0.0005177 \pm 9.755 \times 10^{-6}$ & 0.998 & 0.5 \\
\hline 15 & $p$-Coumaric acid & $0.0003139 \pm 1.434 \times 10^{-5}$ & 0.992 & 0.3 \\
\hline 16 & $p$-Hydroxybenzoic acid & $-0.000008 \pm 1.260 \times 10^{-5}$ & 0.086 & $\mathrm{n} / \mathrm{a}$ \\
\hline 17 & Quinic acid & $-0.0000004 \pm 1.034 \times 10^{-6}$ & 0.032 & $<0.1$ \\
\hline
\end{tabular}

\subsection{Antioxidant Response Element (ARE) Activation}

The ARE fold-increase in HepG2-ARE activation of all compounds relative to the control was $<2$ (Figure 2). Since the ARE fold-increase in HepG2-ARE of examined compounds was $<10$ [15], there were no compounds that could be considered to exert significant ARE induction activity. (-)-Epicatechin showed the strongest ARE activation among all compounds, followed by $p$-coumaric acid, quercetin 3 - $\beta$-D-glucose, and vanillic acid, respectively. Several compounds such as penta-O-galloyl- $\beta$-D-glucose, gallic acid, epicatechin gallate, and quercetin 3- $\beta$-D-glucose at high concentrations were toxic to cells, which did not induce ARE activation.

\subsection{Cell Proliferation Assays}

Cell viability assays were performed to address the cytotoxic effects of the phenolic compounds. A reduction in luminescence absorbance could result from a loss of cell viability and a reduction in cell number. The vehicle DMSO at the highest concentrations used $(0.35 \%)$ did not affect cell number or viability in both A549 and MRC-5 cells, indicating that a reduction in luminescence absorbance in the presence of the tested compounds would indicate a toxic effect of these compounds rather than the vehicle. Among 16 tested compounds, penta-O-galloyl- $\beta$-D-glucose and quercetin 3- $\beta$-D-glucoside had the lowest $\mathrm{IC}_{50}$ values in the $\mathrm{A} 549$ cells (Table 2 ). The $\mathrm{IC}_{50}$ values of penta-O-galloyl- $\beta$-D-glucose and quercetin 3- $\beta$-D-glucoside in MRC-5 cells were 6.11 and $6.89 \mu \mathrm{M}$, respectively (Figure 3). These compounds were also toxic to the MRC- 5 cells. The $\mathrm{IC}_{50}$ values of penta-O-galloyl- $\beta$-D-glucose and quercetin 3- $\beta$-D-glucoside in MRC-5 cells were 10.37 and $12.15 \mu \mathrm{M}$, respectively. Epicatechin gallate had $\mathrm{IC}_{50}$ values for $\mathrm{A} 549$ and MRC-5 cells that were 65.96 and 64.38 , respectively, while $\mathrm{IC}_{50}$ values of quercetin and gallic acid for A549 and MRC-5 cells were 87.74 and 99.47, and >250 and 48.18 , respectively. Other tested compounds had $\mathrm{IC}_{50}$ values $>250 \mu \mathrm{M}$ in both A549 cells and MRC-5 (Table 2). 


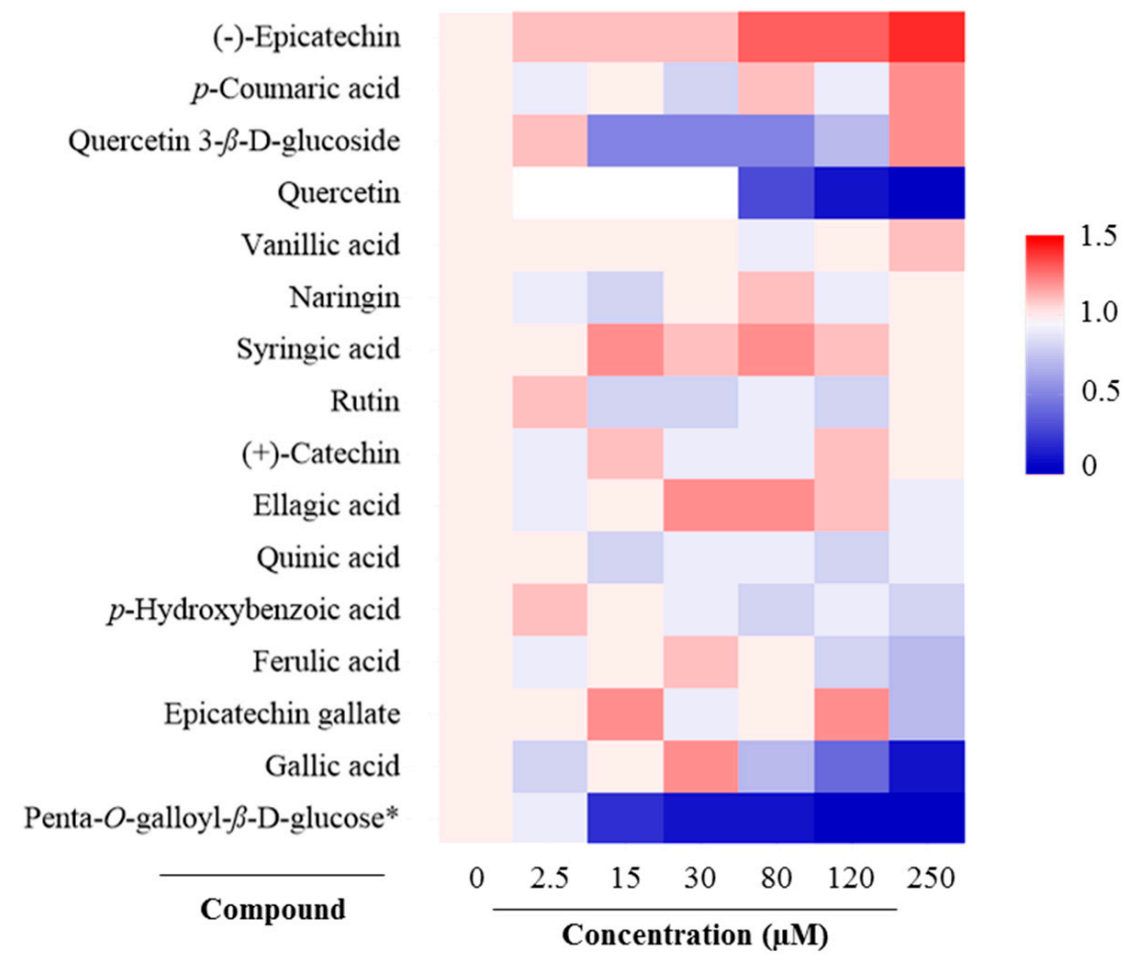

Figure 2. Antioxidant response element (ARE) activation activities of the tested compounds in HepG2-ARE cells. In the heatmap, color represents relative fold-increases in ARE activities in HepG2-ARE cells treated with DMSO and compounds compared with the corresponding vehicle control, the HepG2-ARE cells treated with $0.35 \%$ DMSO only. * Penta-O-galloyl- $\beta$-D-glucose was screened at concentrations of $0,2.5,15,30,80,125,175 \mu \mathrm{M}$, respectively.

Table 2. Half maximal inhibitory concentrations $\left(\mathrm{IC}_{50}\right)$ of phenolic compounds $(\mu \mathrm{M})$ in black walnuts in A549 and MRC-5 cell lines.

\begin{tabular}{ccc}
\hline Compound & A549 Cell Line & MRC-5 Cell Line \\
\hline Penta-O-galloyl- $\beta$-D-glucose & 6.11 & 10.37 \\
Quercetin 3- $\beta$-D-glucoside & 6.89 & 12.15 \\
Epicatechin gallate & 65.96 & 64.38 \\
Quercetin & 87.74 & 99.47 \\
Gallic acid & $>250$ & 48.18 \\
Ellagic acid & $>250$ & $>250$ \\
(-)-Epicatechin & $>250$ & $>250$ \\
Rutin & $>250$ & $>250$ \\
(+)-Catechin & $>250$ & $>250$ \\
Ferulic acid & $>250$ & $>250$ \\
Syringic acid & $>250$ & $>250$ \\
Vanillic acid & $>250$ & $>250$ \\
Naringin & $>250$ & $>250$ \\
$p$-Coumaric acid & $>250$ & $>250$ \\
$p$-Hydroxybenzoic acid & $>250$ & $>250$ \\
Quinic acid & $>250$ & 9.95 \\
DL-Sulforaphane (control) & 16.96 &
\end{tabular}



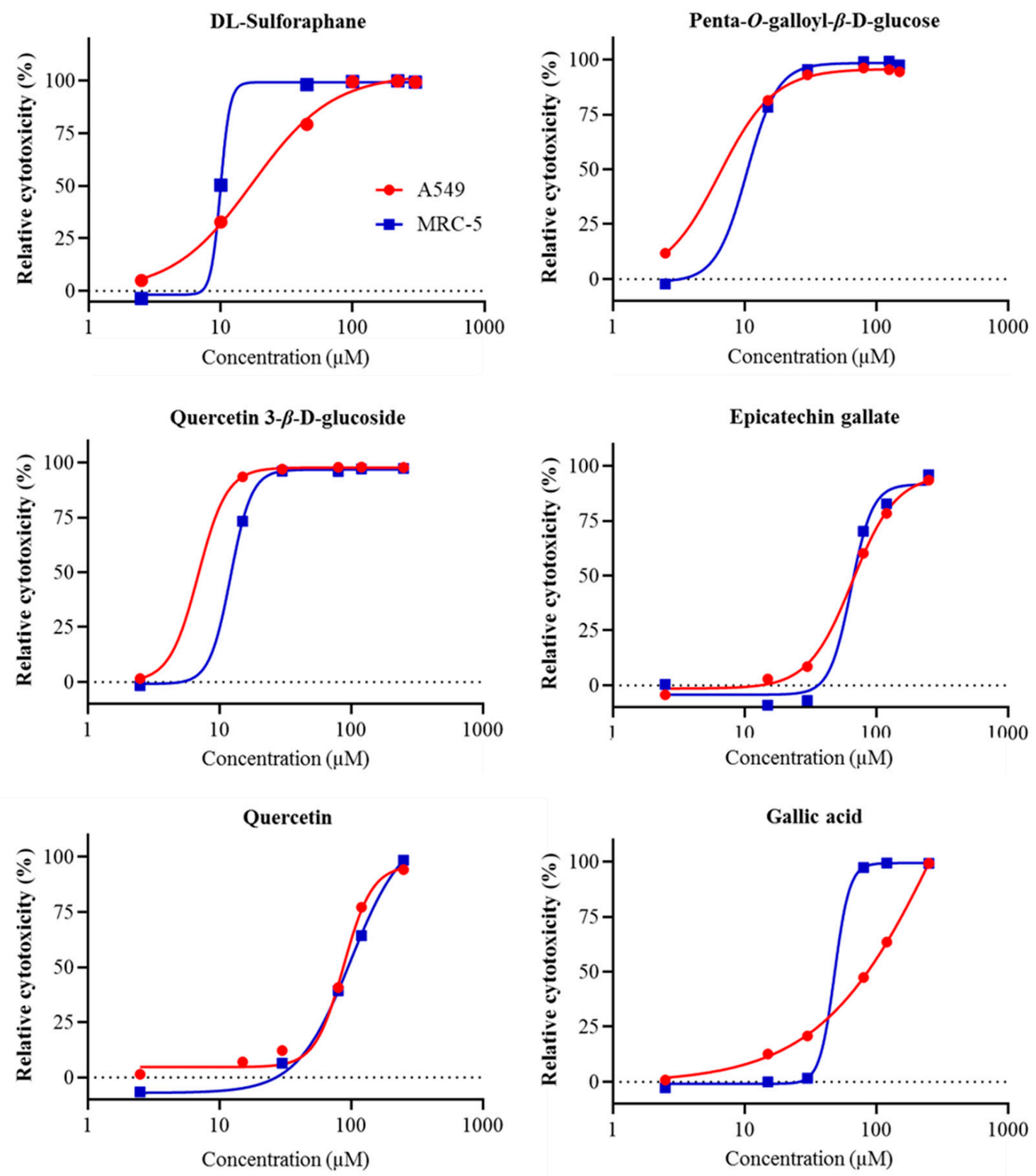

Figure 3. Cytotoxicity (\%) of phenolic compounds (penta-O-galloyl- $\beta$-D-glucose, quercetin 3 - $\beta$-D-glucoside, gallic acid, epicatechin gallate, ellagic acid) and the control (DL-sulforaphane) in A549 and MRC-5 cell lines. Data are expressed as percentages of cytotoxicity in A549 and MRC-5 cells treated with DMSO and the compounds compared with the corresponding vehicle controls that were A549 and MRC-5 cells treated with $0.35 \%$ DMSO only.

\section{Discussion}

Black walnuts have recently been documented as a promising natural source for the medicinal and pharmaceutical industries. The kernels of black walnuts have been reported to possess multiple biological functions which are likely associated with the presence of its bioactive constituents, including polyphenols. In the present study, we utilized HTS technologies to characterize the antioxidant and anticancer activities of 16 phenolic compounds found in black walnut kernels [6,9]. Given the huge availability of black walnuts, the exploration of the biological functions of the bioactive compounds in black walnuts could promote the development of novel applications of black walnut and its by-products, 
which could provide opportunities to utilize the abundant, low-value, renewable materials from black walnut and its by-products into profitable value-added products and thereby potentially increase the sustainability of the black walnut agro-industry.

Our results indicated that several phenolic compounds found in black walnut kernels exert strong antioxidant activities. Out of 16 phenolic compounds tested, 10 compounds (penta-O-galloyl- $\beta$-D-glucose, epicatechin gallate, quercetin, (-)-epicatechin, rutin, quercetin $3-\beta$-D-glucoside, gallic acid, (+)-catechin, ferulic acid, syringic acid) exhibited higher total antioxidant capacity than Trolox. The presence of multiple phenolic compounds also raises the possibility of synergistic activities that are likely responsible for the antioxidant activities observed in black walnuts. Our results indicated that no compound can be considered to exert significant ARE induction activity since all tested compounds had ARE fold-increases relative to the control that were less than 10 . Roy et al. [15] suggested that an ARE fold-increase $>10$ was considered to induce the activity of ARE signaling pathways that functionally regulate the expression of genes encoding over 250 antioxidant and detoxification proteins [16]. Vu et al. [7] observed the variation of antioxidant capacities of different black walnut cultivars, in which Mystry exhibited the highest antioxidant activity among the examined cultivars. Future research will focus on purification and characterization of bioactive compounds and its composition in Mystry that mainly drive the antioxidant activity.

Our results also revealed the anticancer potential of the phenolic compounds in black walnuts. Two phenolic compounds, penta-O-galloyl- $\beta$-D-glucose and quercetin 3- $\beta$-D-glucoside, exhibited antiproliferative activities against both the tumorigenic alveolar epithelial cells (A549) and non-tumorigenic lung fibroblast cells (MRC-5), while no significant inhibitory effects on the growth of these cell lines were observed on other tested compounds. Black walnut and English walnut $(J$. regia L.), another common Juglans species, have been reported to share a similar polyphenolic profile in which all 16 phenolic compounds tested were found both in black walnut and English walnut (Table 3). The total contents of these phenolic compounds in black walnut was lower compared with English walnut [9]. Remarkably, anticancer capacities have been well established both in vivo and in vitro in English walnut. In vivo, English walnut kernels have been shown to inhibit the growth of several types of cancer cells, including colon cancer stem cells, breast cancer cells, and colorectal cancer cells [17-19]. Consumption of English walnut kernels by mice was associated with in vitro tumor cell changes in DNA proliferation and apoptosis [20-22]. Anticancer functions of English walnuts are possibly associated with its polyphenols $[19,23]$, suggesting possible anticancer capacities of black walnuts and its polyphenols.

$\mathrm{Vu}$ et al. [9] reported that the contents of phenolic compounds were widely variable among different black walnut cultivars. Among the six black walnut cultivars whose antioxidant capacities have been examined, the kernel extracts from Mystry and Surprise have been documented to possess the strongest antioxidant activities [7]. Remarkably, penta-O-galloyl- $\beta$-D-glucose only presented in Mystry $(15.2 \mathrm{mg} / \mathrm{kg}$ ) and was not detectable in other cultivars (e.g., Surprise) showing the antioxidant activities (Table 3). The concentration of this compound in black walnut (Mystry) was lower compared with English walnut $(58.6 \mathrm{mg} / \mathrm{kg})$. Due to a huge variation in the contents of phenolic compounds in different black walnut cultivars, it is likely that the antioxidant activities of these extracts were possibly driven by not only penta- $O$-galloyl- $\beta$-D-glucose but also other compounds. Additionally, the presence of multiple phenolic compounds in black walnut raises the possibility of synergistic effects of these compounds that are responsible for the biological activities of black walnuts. 
Table 3. Concentrations of phenolic compounds ( $\mu \mathrm{g} / \mathrm{g}$ of dry weight) in kernels of six black walnut cultivars with their known bioactive activities $[5-7,9,24]$.

\begin{tabular}{|c|c|c|c|c|c|c|c|}
\hline \multirow{2}{*}{ Compound } & \multicolumn{6}{|c|}{ Black Walnut Cultivar } & \multirow{2}{*}{$\begin{array}{c}\text { English } \\
\text { Walnut }^{+}\end{array}$} \\
\hline & Daniel & Hay & Jackson & Kwik Krop & Mystry & Surprise & \\
\hline $\begin{array}{l}\text { Penta-O-galloyl- } \\
\beta \text {-D-glucose }\end{array}$ & $\mathrm{n} / \mathrm{d}$ & $\mathrm{n} / \mathrm{d}$ & $\mathrm{n} / \mathrm{d}$ & $\mathrm{n} / \mathrm{d}$ & $15.2 \pm 2.5$ & $\mathrm{n} / \mathrm{d}$ & $55.9 \pm 7.7$ \\
\hline $\begin{array}{l}\text { Quercetin } \\
\text { 3- } \beta \text {-D-glucoside }\end{array}$ & $\mathrm{n} / \mathrm{d}$ & $3.2 \pm 0.1$ & $1.6 \pm 0.2$ & $\mathrm{n} / \mathrm{d}$ & $2.1 \pm 0.3$ & $1.8 \pm 0.3$ & $3.7 \pm 0.2$ \\
\hline $\begin{array}{l}\text { Epicatechin } \\
\text { gallate }\end{array}$ & $13.2 \pm 0.5$ & $7.0 \pm 0.6$ & $3.6 \pm 0.7$ & $\mathrm{n} / \mathrm{d}$ & $2.0 \pm 0.2$ & $6.0 \pm 0.7$ & $4.9 \pm 1.5$ \\
\hline Gallic acid & $\mathrm{n} / \mathrm{d}$ & $1.4 \pm 0.2$ & $0.7 \pm 0.2$ & $0.5 \pm 0.03$ & $4.3 \pm 0.3$ & $1.0 \pm 0.03$ & $8.1 \pm 0.7$ \\
\hline Ellagic acid & $30.4 \pm 1.0$ & $40.5 \pm 5.9$ & $61.1 \pm 3.7$ & $11.4 \pm 2.0$ & $65.7 \pm 4.8$ & $72.1 \pm 8.3$ & $98.4 \pm 20.6$ \\
\hline Rutin & $\mathrm{n} / \mathrm{d}$ & $\mathrm{n} / \mathrm{d}$ & $\mathrm{n} / \mathrm{d}$ & $1.7 \pm 0.6$ & $4.2 \pm 1.3$ & $\mathrm{n} / \mathrm{d}$ & $2.7 \pm 0.3$ \\
\hline$(+)$-Catechin & $\mathrm{n} / \mathrm{d}$ & $\mathrm{n} / \mathrm{d}$ & $\mathrm{n} / \mathrm{d}$ & $\mathrm{n} / \mathrm{d}$ & $\mathrm{n} / \mathrm{d}$ & $0.6 \pm 0.01$ & $47.9 \pm 3.5$ \\
\hline Ferulic acid & $\mathrm{n} / \mathrm{d}$ & $\mathrm{n} / \mathrm{d}$ & $\mathrm{n} / \mathrm{d}$ & $0.7 \pm 0.04$ & $0.6 \pm 0.06$ & $4.9 \pm 0.08$ & $0.9 \pm 0.1$ \\
\hline Syringic acid & $7.3 \pm 1.3$ & $\mathrm{n} / \mathrm{d}$ & $7.7 \pm 1.4$ & $\mathrm{n} / \mathrm{d}$ & $9.5 \pm 2.1$ & $\mathrm{n} / \mathrm{d}$ & $7.3 \pm 2.2$ \\
\hline Vanillic acid & $\mathrm{n} / \mathrm{d}$ & $9.9 \pm 2.6$ & $8.7 \pm 1.7$ & $\mathrm{n} / \mathrm{d}$ & $6.9 \pm 1.2$ & $\mathrm{n} / \mathrm{d}$ & $7.3 \pm 1.8$ \\
\hline Naringin & $0.5 \pm 0.1$ & $\mathrm{n} / \mathrm{d}$ & $\mathrm{n} / \mathrm{d}$ & $0.3 \pm 0.1$ & $0.5 \pm 0.2$ & $4.9 \pm 0.1$ & $0.3 \pm 0.04$ \\
\hline$p$-Coumaric acid & $\mathrm{n} / \mathrm{d}$ & $0.2 \pm 0.03$ & $0.2 \pm 0.03$ & $0.2 \pm 0.1$ & $0.3 \pm 0.02$ & $0.3 \pm 0.1$ & $0.5 \pm 0.1$ \\
\hline $\begin{array}{l}p \text {-Hydroxybenzoic } \\
\text { acid }\end{array}$ & $\mathrm{n} / \mathrm{d}$ & $\mathrm{n} / \mathrm{d}$ & $\mathrm{n} / \mathrm{d}$ & $\mathrm{n} / \mathrm{d}$ & $\mathrm{n} / \mathrm{d}$ & $\mathrm{n} / \mathrm{d}$ & $1.2 \pm 0.5$ \\
\hline Quinic acid & $4.7 \pm 0.2$ & $2.4 \pm 0.1$ & $1.4 \pm 0.2$ & $4.2 \pm 0.2$ & $2.4 \pm 0.3$ & $3.9 \pm 0.5$ & $6.8 \pm 0.4$ \\
\hline Quercetin & $\mathrm{n} / \mathrm{q}$ & $\mathrm{n} / \mathrm{q}$ & $\mathrm{n} / \mathrm{q}$ & $\mathrm{n} / \mathrm{q}$ & $\mathrm{n} / \mathrm{q}$ & $\mathrm{n} / \mathrm{q}$ & $\mathrm{n} / \mathrm{q}$ \\
\hline (-)-Epicatechin & $\mathrm{n} / \mathrm{q}$ & $\mathrm{n} / \mathrm{q}$ & $\mathrm{n} / \mathrm{q}$ & $\mathrm{n} / \mathrm{q}$ & $\mathrm{n} / \mathrm{q}$ & $\mathrm{n} / \mathrm{q}$ & $3.9 \pm 0.01$ \\
\hline \multicolumn{8}{|c|}{ Biological Activity of Kernel Extracts from Black Walnuts } \\
\hline Antioxidant & ++ & + & ++ & ++ & +++ & +++ & $\mathrm{n} / \mathrm{c}$ \\
\hline $\begin{array}{l}\text { Antibacterial * } \\
\text { Anti- }\end{array}$ & . & . & . & . & +++ & +++ & $\mathrm{n} / \mathrm{c}$ \\
\hline $\begin{array}{l}\text { inflammatory } \\
\text { potential }\end{array}$ & + & $\mathrm{n} / \mathrm{a}$ & $\mathrm{n} / \mathrm{a}$ & $\mathrm{n} / \mathrm{a}$ & + & +++ & $\mathrm{n} / \mathrm{c}$ \\
\hline
\end{tabular}

The results from HTS assays indicated penta-O-galloyl- $\beta$-D-glucose as a potent bioactive compound. This compound exhibited strong antioxidant and anticancer capacities. The fold-increase over Trolox of penta-O-galloyl- $\beta$-D-glucose was 11.5 , whereas the $\mathrm{IC}_{50}$ value of this compound for the tumorigenic alveolar epithelial cell line (A549) was 6.11. Zhang et al. [10] reported 1, 2, 3, 4, 6-penta-O-galloyl- $\beta$-D-glucose, a hydrolysable tannin, as a polyphenolic compound highly enriched in several plants and herbs such as Acer truncatum, Paeonia suffruticosa, Rhus chinensis, Schinus terebinthifolius, and Terminalia chebula. Previous studies have documented a variety of biological functions of penta-O-galloyl- $\beta$-D-glucose, including antidiabetic, antibacterial, antioxidant, anticancer, antiangiogenic, antivirus, and anti-inflammatory activities [10,25]. This compound has been shown to possess anticancer effects against multiple cancer cells including lung cancer, prostate cancer, and breast cancer [26-28]. Huh et al. [28] reported antitumor activities of 1, 2, 3, 4, 6-penta-O-galloyl- $\beta$-D-glucose that primarily inhibited angiogenesis through cyclooxygenase-2 and phospho-p38 mitogen-activated protein kinase (MAPK)-dependent pathways. Additionally, Bae et al. [29] suggested 1,2,3,4,6-penta-O-galloyl- $\beta$-D-glucose as a potential candidate antiviral drug to treat varicella-zoster virus (VZV)-associated diseases (e.g., chickenpox) due to its significant suppressive inhibitory effect on VZV-induced c-Jun N-terminal kinase (JNK) activation, expression of viral immediate-early 62 (IE62) protein, and VZV replication. Vu et al. [9] quantified the amount of penta-O-galloyl- $\beta$-D-glucose in kernel extracts from 11 different black walnut cultivars and reported that the highest amount of penta-O-galloyl- $\beta$-D-glucose was found in Mystry $(15.2 \mathrm{mg} / \mathrm{kg})$. This cultivar has been documented to possess multiple bioactive activities including antioxidant, antibacterial, and 
anti-inflammatory potential. Future research might focus on exploring the anticancer properties of Mystry and its bioactive constituents.

\section{Materials and Methods}

\subsection{Sample Preparation}

Chemicals including (+)-catechin, (-)-epicatechin gallate, ellagic acid, ferulic acid, gallic acid, naringin, $p$-coumaric acid, $p$-hydroxybenzoic acid, penta-O-galloyl- $\beta$-D-glucose, quinic acid, quercetin, quercetin-3- $\beta$-D-glucoside, rutin, syringic acid, vanillic acid, Trolox, DL-sulforaphane, and tert-butylhydroquinone (TBHQ) were purchased from Sigma-Aldrich (purity $\geq 95 \%$, Sigma-Aldrich, St. Louis, MO, USA). The compound, glansreginin A, was not included in this study since this compound was not commercially available. In all assays, all chemicals were solubilized in 100\% DMSO (dimethyl sulfoxide, tissue-culture grade, Sigma-Aldrich) to facilitate acoustic transfer and were transferred acoustically to the assay plates using an Echo Liquid Handler (Echo ${ }^{\circledR}$ 555, Beckman Coulter Inc., Brea, CA, USA). All compounds were evaluated for antioxidant and antitumor activities in dose-response assays at 7 concentrations of $0,2.5,15,30,80,120$, and $250 \mu \mathrm{M}$, except for penta-O-galloyl- $\beta$-D-glucose, Trolox, DL-sulforaphane, and TBHQ. The concentrations of penta-O-galloyl- $\beta$-D-glucose tested were 0 , $2.5,15,30,80,125$, and $175 \mu \mathrm{M}$, and Trolox was screened at concentrations of $0,5,10,20,40,80$, and $120 \mu \mathrm{M}$, whereas DL-sulforaphane and TBHQ were evaluated at concentrations of $0,2.5,10,45,100$, 220 , and $300 \mu \mathrm{M}$. DMSO was used for backfill and the highest final concentration of DMSO added into the cells was $0.35 \%$. The cells treated with $0.35 \%$ DMSO and without DMSO were included as vehicle controls in the assays. In all screening assays, all compounds were tested with one replicate per concentration per assay to generate a linear curve of each activity for each compound. The vehicles and positive controls (DL-sulforaphane, TBHQ) were screened via four replicates to identify variability of data.

\subsection{Cell Lines}

An Nrf2 antioxidant response element (ARE) reporter HepG2 cell line, a stably transfected liver cell line expressing a firefly luciferase gene under the control of the ARE, was purchased from BPS Bioscience (San Diego, CA, USA). The human alveolar epithelial cell line A549 and the human lung fibroblast cell line MRC-5 were obtained from American Type Culture Collection (ATCC) (CCL-185 and CCL-171, ATCC, Manassas, VA, USA). The HepG2-ARE cells were grown in modified Eagle's medium (MEM) supplemented with GlutaMAX, 10\% fetal calf serum (FBS) and 600ug/mL Geneticin (Thermo Fisher Scientific, Waltham, MA, USA). The tumorigenic alveolar epithelial cells (A549) and non-tumorigenic lung fibroblast cells (MRC-5) were grown in RPMI medium supplemented with $10 \%$ FBS. All cells were grown and maintained at $37^{\circ} \mathrm{C}$ in a humidified incubator with $5 \% \mathrm{CO}_{2}$.

\subsection{Total Antioxidant Capacity}

The antioxidant capacity of the phenolic compounds was evaluated using a total antioxidant capacity (TAC) colorimetric assay kit (K274-100, BioVision, CA, USA), according to the manufacturer's instructions. Briefly, the phenolic compounds tested at 7 concentrations (as described above) were added to 384-well plates. Subsequently, $\mathrm{Cu}^{2+}$ working solution $(12.5 \mu \mathrm{L} /$ well $)$ was added into the sample wells. The 384-well plates were incubated for $1.5 \mathrm{~h}$ at room temperature and the absorbance of the samples was then read at $570 \mathrm{~nm}$ using a microplate reader (Enspire, Perkin Elmer Inc., Waltham, MA, USA). Trolox was used to standardize the antioxidant capacity, as recommended by the manufacturer. A Trolox standard curve was included, and the total antioxidant capacity of the phenolic compounds was interpolated and expressed as Trolox equivalent (mM) from a seven-parameter logistic curve of the Trolox control using curve-fitting software. 


\subsection{Antioxidant Response Element (ARE) Activation}

The impact of the phenolic compounds on ARE activation in the HepG2-ARE cell line was evaluated using Steady-Glo ${ }^{\circledR}$ Luciferase assay system (E2510, Promega, Madison, WI, USA), following the manufacturer's instructions. In brief, the HepG2 -ARE cells were seeded at a density of 10,000 cells/well in 384-well plates containing $50 \mu \mathrm{L}$ of the complete media per well using a Multidrop Combi dispenser (Thermo Fisher Scientific, Waltham, MA, USA) and then the plate cultures were incubated at $37^{\circ} \mathrm{C}$ in a $5 \% \mathrm{CO}_{2}$ humidified incubator for $20 \mathrm{~h}$. The HepG2-ARE cells were incubated with compounds for $18 \mathrm{~h}$. The known ARE activator TBHQ was used as a positive control and the cells treated with $0.35 \%$ DMSO and without compounds tested served as a vehicle control. The cells in the absence of DMSO and the compounds were utilized for measuring the background luminescence. The reporter activity was measured by the addition of $25 \mu \mathrm{L}$ Steady-Glo ${ }^{\circledR}$ luciferase assay reagent (Promega) for $30 \mathrm{~min}$ using the Multidrop Combi dispenser (Thermo Fisher Scientific). The luminescence intensities of the 384-well plates were read on Enspire microplate reader (Perkin Elmer Inc.). Percent cytotoxicity of compounds was normalized to the positive and negative controls on each assay plate.

\subsection{Cell Proliferation Assays}

Influence of the phenolic compounds on cell growth in the tumorigenic alveolar epithelial cells (A549) and non-tumorigenic lung fibroblast cell (MRC-5) cell lines was investigated using the CellTiter-Glo ${ }^{\circledR}$ cell viability assay kit (G7571, BioVision, CA, USA), according to the manufacturer's instructions. Briefly, the A549 and MRC-5 cells were seeded at densities of 8000 and 3000 cells per well, respectively, in 384-well plates and were then incubated in a $5 \% \mathrm{CO}_{2}$ humidified incubator at $37{ }^{\circ} \mathrm{C}$. The cultures were treated with the phenolic compounds and DL-Sulphorane (a known antiproliferative agent as a positive control) at 7 final concentrations (as mentioned above) and a vehicle (0.35\% DMSO). After 72h of incubation, CellTiter-Glo Luminescent assay reagent (Promega) was dispensed at a volume of $10 \mu \mathrm{L}$ per well into the 384-well plates for $10 \mathrm{~min}$ using the Matrix Wellmate dispenser (Thermo Fisher Scientific). The plates were allowed to incubate at room temperature for 20 min and then the luminescence was read using an Enspire microplate reader (Perkin Elmer Inc.)

\subsection{Data Analysis}

For total antioxidant capacity analysis, linear regression analysis was performed to identify the linear regression equation for each compound using GraphPad Prism 8 (San Diego, CA, USA). The coefficient of the compound equation was compared with the coefficient of the Trolox control to determine the relative total antioxidant capacity of each compound. Fold-increase over Trolox was calculated by dividing the coefficient of the compound models by the coefficient of the Trolox control. The compounds that exhibited a fold-increase over Trolox greater than 5 were considered to possess significant total antioxidant capacity [15].

The ARE fold induction of the compounds was measured by dividing the luminescence absorbance of the treatment by the specific luminescence absorbance of the control sample and multiplying by 100. The control sample (in the presence of DMSO vehicle and without the compounds) was set at $100 \%$. The compounds that had ARE fold induction to 10-fold over the vehicle controls in one or more concentrations were considered to have significant ARE induction activity [15].

The relative cytotoxicity (\%) of the phenolic compounds was calculated by dividing the specific luminescence absorbance of the treated sampled by the specific luminescence absorbance of the control sample and multiplying by 100. The control sample (in the presence of DMSO vehicle and without the compounds) was set at $100 \%$. Non-linear regression analysis of data was performed to identify the dose-response curve for each compound. The $\mathrm{IC}_{50}$ values (half maximal inhibitory concentration) of each compound were determined from the dose-response curve for the A549 and MRC-5 cell lines using GraphPad Prism 8. The compounds that exhibited IC 50 values $<10 \mu \mathrm{M}$ in the A549 cell line and had no toxic effects on the control cell line MRC- 5 were considered to be potent antiproliferative compounds. 


\section{Conclusions}

We identified the antioxidant and anticancer potentials of phenolic compounds found in black walnuts. Out of 16 tested compounds, several compounds had remarkable antioxidant activities and two compounds had strong anticancer activities. Penta- $O$-galloyl- $\beta$-D-glucose exhibited the strongest antioxidant and antiproliferative activities against both the tumorigenic alveolar epithelial cells (A549) and non-tumorigenic lung fibroblast cells (MRC-5) among the tested compounds. Antioxidant activities of black walnut cultivars are likely correlated with the synergistic effects of phenolic compounds in black walnut. Black walnut extracts possibly possess anticancer activity. Penta-O-galloyl- $\beta$-D-glucose has been previously documented to exert a wide range of bioactive activities. Our results support the notion that penta-O-galloyl- $\beta$-D-glucose could be a potential bioactive compound for the cosmetic and pharmaceutical industries.

Supplementary Materials: The following are available online. Figure S1: Data distribution of controls (Trolox, DL-sulforaphane, tert- butylhydroquinone) in total antioxidant capacity and antioxidant response element (ARE) activation assays. Figure S2: Data distribution of controls (Trolox, DL-sulforaphane) in cytotoxicity assays.

Author Contributions: Conceptualization: C.-H.L., A.R., K.-V.H.; data curation: A.R., S.F.; formal analysis: K.-V.H.; writing—original draft preparation: K.-V.H.; writing—review and editing: all authors; investigation and funding acquisition: C.-H.L. All authors have read and agreed to the published version of the manuscript.

Funding: This work was supported by the USDA/ARS Dale Bumpers Small Farm Research Center, Agreement number 58-6020-6-001 from the USDA Agricultural Research Service, Center for Agroforestry at University of Missouri, and Missouri Department of Agriculture Specialty Crop Block Grant Program (SCBGP) \#16SCBGPMO0003.

Acknowledgments: We would like to thank the Center for Agroforestry at University of Missouri, USDA/ARS Dale Bumpers Small Farm Research Center, and Missouri Department of Agriculture Specialty Crop Block Grant Program for supporting this research.

Conflicts of Interest: The authors declare no conflict of interest.

\section{References}

1. Randolph, K.C.; Rose, A.K.; Oswalt, C.M.; Brown, M.J. Status of Black Walnut (Juglans nigra L.) in the Eastern United States in Light of the Discovery of Thousand Cankers Disease. Castanea 2013, 78, 2-14. [CrossRef]

2. Coggeshall, M.V. Black Walnut: A Nut Crop for the Midwestern United States. HortScience 2011, 46, 340-342. [CrossRef]

3. Nolan, J.M.; Robbins, M. Cultural Conservation of Medicinal Plant Use in the Ozarks. Hum. Organ. 1999, 58, 67-72. [CrossRef]

4. Câmara, C.R.S.; Schlegel, V. A Review on the Potential Human Health Benefits of the Black Walnut: A Comparison with the English Walnuts and Other Tree Nuts. Int. J. Food Prop. 2015, 19, 2175-2189. [CrossRef]

5. Ho, K.-V.; Schreiber, K.L.; Vu, D.C.; Rottinghaus, S.M.; Jackson, D.E.; Brown, C.R.; Lei, Z.; Sumner, L.W.; Coggeshall, M.V.; Lin, C.-H. Black Walnut (Juglans nigra) Extracts Inhibit Proinflammatory Cytokine Production From Lipopolysaccharide-Stimulated Human Promonocytic Cell Line U-937. Front. Pharmacol. 2019, 10. [CrossRef]

6. Ho, K.-V.; Lei, Z.; Sumner, L.W.; Coggeshall, M.V.; Hsieh, H.-Y.; Stewart, G.C.; Lin, C.-H. Identifying Antibacterial Compounds in Black Walnuts (Juglans nigra) Using a Metabolomics Approach. Metabolites 2018, 8, 58. [CrossRef]

7. Vu, D.C.; Park, J.; Ho, K.-V.; Sumner, L.W.; Lei, Z.; Greenlief, C.M.; Mooney, B.; Coggeshall, M.V.; Lin, C.-H. Identification of health-promoting bioactive phenolics in black walnut using cloud-based metabolomics platform. J. Food Meas. Charact. 2019, 14, 770-777. [CrossRef]

8. Reid, W.; Coggeshall, M.V.; Garrett, H.E.; Van Sambeek, J.W. Growing Black Walnut for Nut Production. Available online: http://www.centerforagroforestry.org/pubs/walnutNuts.pdf (accessed on 29 August 2020).

9. Vu, D.C.; Vo, P.H.; Coggeshall, M.V.; Lin, C.-H. Identification and Characterization of Phenolic Compounds in Black Walnut Kernels. J. Agric. Food Chem. 2018, 66, 4503-4511. [CrossRef] 
10. Zhang, J.; Li, L.; Kim, S.-H.; Hagerman, A.E.; Lü, J. Anti-Cancer, Anti-Diabetic and Other Pharmacologic and Biological Activities of Penta-Galloyl-Glucose. Pharm. Res. 2009, 26, 2066-2080. [CrossRef] [PubMed]

11. Actis-Goretta, L.; Romanczyk, L.J.; Rodríguez, C.A.; Kwik-Uribe, C.; Keen, C.L. Cytotoxic effects of digalloyl dimer procyanidins in human cancer cell lines. J. Nutr. Biochem. 2008, 19, 797-808. [CrossRef]

12. Chen, Q.; Li, P.; Xu, Y.; Li, Y.; Tang, B. Isoquercitrin inhibits the progression of pancreatic cancer in vivo and in vitro by regulating opioid receptors and the mitogen-activated protein kinase signalling pathway. Oncol. Rep. 2014, 33, 840-848. [CrossRef] [PubMed]

13. Macarrón, R.; Banks, M.N.; Bojanic, D.; Burns, D.J.; Cirovic, D.A.; Garyantes, T.; Green, D.V.S.; Hertzberg, R.P.; Janzen, W.P.; Paslay, J.W.; et al. Impact of high-throughput screening in biomedical research. Nat. Rev. Drug Discov. 2011, 10, 188-195. [CrossRef] [PubMed]

14. Leavell, M.D.; Singh, A.H.; Kaufmann-Malaga, B.B. High-throughput screening for improved microbial cell factories, perspective and promise. Curr. Opin. Biotechnol. 2020, 62, 22-28. [CrossRef] [PubMed]

15. Roy, A.; McDonald, P.; Timmermann, B.N.; Gupta, M.; Chaguturu, R. Bioactivity Profiling of Plant Biodiversity of Panama by High Throughput Screening. Nat. Prod. Commun. 2019, 14, 71-74. [CrossRef]

16. Dong, Z.; Kundu, J.K.; Na, H.-K. Nrf2 as a Master Redox Switch in Turning on the Cellular Signaling Involved in the Induction of Cytoprotective Genes by Some Chemopreventive Phytochemicals. Planta Med. 2008, 74, 1526-1539.

17. Koh, S.-J.; Choi, Y.I.; Kim, Y.; Kim, Y.-S.; Choi, S.-W.; Kim, J.-W.; Kim, B.G.; Lee, K.L. Walnut phenolic extract inhibits nuclear factor kappaB signaling in intestinal epithelial cells, and ameliorates experimental colitis and colitis-associated colon cancer in mice. Eur. J. Nutr. 2018, 58, 1603-1613. [CrossRef]

18. Lee, J.; Kim, Y.-S.; Lee, J.H.; Heo, S.C.; Lee, K.L.; Choi, S.-W.; Kim, Y. Walnut Phenolic Extract and Its Bioactive Compounds Suppress Colon Cancer Cell Growth by Regulating Colon Cancer Stemness. Nutrients 2016, 8, 439. [CrossRef]

19. Sánchez-González, C.; Ciudad, C.J.; Noé, V.; Izquierdo-Pulido, M. Health benefits of walnut polyphenols: An exploration beyond their lipid profile. Crit. Rev. Food Sci. Nutr. 2015, 57, 3373-3383. [CrossRef]

20. Hardman, W.E.; Ion, G. Suppression of Implanted MDA-MB 231 Human Breast Cancer Growth in Nude Mice by Dietary Walnut. Nutr. Cancer 2008, 60, 666-674. [CrossRef]

21. Nagel, J.M.; Brinkoetter, M.; Magkos, F.; Liu, X.; Chamberland, J.P.; Shah, S.; Zhou, J.; Blackburn, G.; Peradze, N. Dietary walnuts inhibit colorectal cancer growth in mice by suppressing angiogenesis. Nutrition 2012, 28, 67-75. [CrossRef]

22. Reiter, R.J.; Tan, D.-X.; Manchester, L.C.; Korkmaz, A.; Fuentes-Broto, L.; Hardman, W.E.; Rosales-Corral, S.A.; Qi, W. A Walnut-Enriched Diet Reduces the Growth of LNCaP Human Prostate Cancer Xenografts in Nude Mice. Cancer Investig. 2013, 31, 365-373. [CrossRef] [PubMed]

23. Hardman, W.E. Walnuts have potential for cancer prevention and treatment in mice. J. Nutr. 2014, 144, 555S-560S. [CrossRef] [PubMed]

24. Figueroa, F.; Marhuenda, J.; Cerdá, B.; Zafrilla, P.; Martínez-Cachá, A.; Tejada, L.; Mulero, J. HPLC-DAD determination and availability of phenolic compounds in 10 genotypes of walnuts. Int. J. Food Prop. 2016, 20, $1-33$.

25. Torres-León, C.; Ventura-Sobrevilla, J.; Serna-Cock, L.; Ascacio-Valdés, J.A.; Contreras-Esquivel, J.; Aguilar, C.N. Pentagalloylglucose (PGG): A valuable phenolic compound with functional properties. J. Funct. Foods 2017, 37, 176-189. [CrossRef]

26. Hu, H.; Lee, H.-J.; Jiang, C.; Zhang, J.; Wang, L.; Zhao, Y.; Xiang, Q.; Lee, E.-O.; Kim, S.-H.; Lü, J. Penta-1,2,3,4,6-O-galloyl- $\beta$-D-glucose induces p53 and inhibits STAT3 in prostate cancer cells in vitro and suppresses prostate xenograft tumor growth in vivo. Mol. Cancer Ther. 2008, 7, 2681-2691. [CrossRef]

27. Yu, W.S.; Jeong, S.-J.; Kim, J.-H.; Lee, H.-J.; Song, H.S.; Kim, M.-S.; Ko, E.; Lee, H.-J.; Khil, J.-H.; Jang, H.-J.; et al. The Genome-Wide Expression Profile of 1,2,3,4,6-Penta-O-Galloyl- $\beta$-D-Glucose-Treated MDA-MB-231 Breast Cancer Cells: Molecular Target on Cancer Metabolism. Mol. Cells 2011, 32, 123-132. [CrossRef] 
28. Huh, J.-E.; Lee, E.-O.; Kim, M.-S.; Kang, K.-S.; Kim, C.-H.; Cha, B.-C.; Dong, Z.; Kim, S.-H. Penta-O-galloyl-beta-D-glucose suppresses tumor growth via inhibition of angiogenesis and stimulation of apoptosis: Roles of cyclooxygenase-2 and mitogen-activated protein kinase pathways. Carcinogenesis 2005, 26, 1436-1445. [CrossRef]

29. Bae, S.; Kim, S.Y.; Do, M.H.; Lee, C.H.; Song, Y.-J. 1,2,3,4,6-Penta-O-galloyl- $\beta$-D-glucose, a bioactive compound in Elaeocarpus sylvestris extract, inhibits varicella-zoster virus replication. Antivir. Res. 2017, 144, 266-272. [CrossRef]

Sample Availability: Samples of the compounds mentioned in this study are available from the authors.

(C) 2020 by the authors. Licensee MDPI, Basel, Switzerland. This article is an open access article distributed under the terms and conditions of the Creative Commons Attribution (CC BY) license (http://creativecommons.org/licenses/by/4.0/). 